\title{
Responsabilidad social universitaria en Latinoamérica. Los casos de URSULA y AUSJAL
}

University social responsibility in Latin-American. The cases of URSULA and AUSJAL

\section{Volumen 19, Número 3 \\ Setiembre-Diciembre}

pp. 1-27

\section{Ricardo Gaete Quezada Juliana Álvarez Rodríguez}

\section{Citar este documento según modelo APA}

Gaete Quezada, Ricardo y Álvarez Rodríguez, Juliana. (2019). Responsabilidad social universitaria en Latinoamérica. Los casos de URSULA y AUSJAL. Revista Actualidades Investigativas en Educación, 19(3), 1-27. Doi. 10.15517/aie.v19i3.38637 


\title{
Responsabilidad social universitaria en Latinoamérica. Los casos de URSULA y AUSJAL

\author{
University social responsibility in Latin-American. The cases of URSULA and AUSJAL
}

\author{
Ricardo Gaete Quezada ${ }^{1}$ \\ Juliana Álvarez Rodríguez ${ }^{2}$
}

\begin{abstract}
Resumen: La relevancia social de las instituciones de educación superior ha aumentado considerablemente en el contexto de desarrollar sociedades más sostenibles, democráticas e inclusivas, en las que la generación y transmisión del conocimiento posee un valor cada vez mayor. Así, el objetivo del artículo es analizar la presencia del concepto de responsabilidad social universitaria en la planificación estratégica de las instituciones pertenecientes a la Unión de Responsabilidad Social Universitaria Latinoamericana (URSULA, 2016) y la Asociación de Universidades Confiadas a la Compañía de Jesús en América Latina (AUSJAL), como ejemplos de redes interuniversitarias latinoamericanas que pretenden fortalecer el rol de las universidades en la Región. Mediante un análisis de contenido cuantitativo se recopila información sobre la presencia de los términos responsabilidad social o socialmente responsable en las declaraciones de misión y visión institucional, utilizando procedimientos de estadística descriptiva para el análisis de los datos mediante la elaboración de figuras y tablas de frecuencia. Los resultados evidencian una baja frecuencia de los aspectos relacionados con el comportamiento socialmente responsable en las declaraciones de misión y visión analizadas, concluyéndose que es recomendable mejorar la coherencia de la filosofía corporativa declarada en los planes estratégicos de las instituciones universitarias latinoamericanas adscritas a ambas iniciativas estudiadas, permitiendo consolidar más efectivamente el concepto de responsabilidad social universitaria tanto en la cultura organizacional como en el funcionamiento operativo de las instituciones que pertenecen a ambas iniciativas.
\end{abstract}

Palabras clave: Educación superior, responsabilidad social universitaria, planificación estratégica, análisis de contenidos.

\begin{abstract}
The social relevance of higher education institutions has increased considerably in the context of developing more sustainable, democratic and inclusive societies, in which the generation and transmission of knowledge has a growing value. Thus, the aim of the article is to analyze the presence of the concept of university social responsibility in the strategic planning of the institutions belonging to the Union of Latin American University Social Responsibility (URSULA in Spanish) and the Association of Confident Universities to the Society of Jesus in Latin America (AUSJAL in Spanish), as examples of Latin American interuniversity networks that aim to strengthen the role of universities in the Region. Through an analysis of quantitative content, information is gathered about the presence of social responsibility or socially responsible terms in mission statements and institutional vision, using descriptive statistics procedures for the analysis of data by drawing figures and frequency tables. The results show a low frequency of the aspects related to socially responsible behavior in the mission and vision statements analyzed, concluding that it is advisable to improve the coherence of the corporate philosophy declared in the strategic plans of the Latin American university institutions attached to both initiatives studied, allowing to consolidate more effectively the concept of university social responsibility both in the organizational culture and in the operational functioning of the institutions that belong to both initiatives.
\end{abstract}

Key words: Higher Education, university social responsibility, strategic planning, content analysis.

\footnotetext{
${ }_{1}^{1}$ Docente de la Universidad Antofagasta, Facultad de Ciencias Sociales, Artes y Humanidades, Chile. Orcid http://orcid.org/0000-0003-2359-2304. Dirección electrónica: ricardo.gaete@uantof.cl

2 Profesora Investigadora de la Universidad Juárez Autónoma de Tabasco, México. Orcid http://orcid.org/0000-0001-6831-4303. Dirección electrónica: juliana.alvarez@ujat.mx
}

Artículo recibido: 25 de marzo, 2019

Enviado a corrección: 11 de junio, 2019

Aprobado: 5 de agosto, 2019 


\section{Introducción}

Los cambios políticos, sociales, económicos y medioambientales acontecidos en el siglo XXI, plantean a las universidades el desafío de revisar los principales aspectos de su misión y visión, adecuando sus funciones de docencia, investigación, vinculación, extensión y gestión universitaria a los requerimientos de la sociedad contemporánea, cada vez más dependiente de la generación y transmisión del conocimiento estableciendo con ellos nuevos y complejos desafíos para las universidades modernas.

En el contexto descrito anteriormente, desde el año 2000 a la fecha se ha consolidado el concepto de responsabilidad social universitaria (RSU) en varios países de lberoamérica (Martí y Martí-Vilar, 2013; Olarte-Mejía y Ríos-Osorio, 2015; Vallaeys y Álvarez, 2019), como expresión de la incorporación de una serie de elementos relevantes para la sociedad relacionados con los impactos sociales, económicos y medioambientales de cada organización, así como con los aspectos relativos a la ética y la transparencia en la relación de la universidad con una serie de stakeholders o partes interesadas en el quehacer de las instituciones de educación superior (IES) a nivel mundial (Gaete, 2015a; Larrán y Andrades, 2015; Licandro y Yepes, 2018; Martí-Noguera et al, 2018; Vallaeys, 2018).

En virtud de lo anterior, el presente estudio se orienta por las siguientes preguntas de investigación:

1. ¿De qué manera las universidades adscritas a las redes interuniversitarias que promueven la RSU en América Latina incluyen los términos responsabilidad social o socialmente responsable en sus declaraciones de misión y visión institucional?

2. ¿De qué manera los ejes y sub-ejes del modelo de Vallaeys et al (2009) están incorporados en las declaraciones de misión y visión institucional de las universidades adscritas a redes interuniversitarias que promueven la RSU en América Latina?

Por ello, el propósito fundamental de este artículo es analizar la presencia de los principales aspectos del concepto de RSU en las declaraciones de misión y visión de las universidades adscritas a la Unión de Responsabilidad Social Universitaria Latinoamericana (URSULA) y a la Asociación de Universidades Confiadas a la Compañía de Jesús en América Latina (AUSJAL), como espacios latinoamericanos en los cuales la RSU es consagrada con un aspecto relevante dentro del funcionamiento de las instituciones universitarias que integran ambos conglomerados. 
Así, mediante un análisis de contenido de tipo cuantitativo se revisaron las declaraciones de misión y visión de las universidades e instituciones de educación superior (IES) adscritas a URSULA y AUSJAL respectivamente, en la búsqueda de referencias a los conceptos de responsabilidad social o socialmente responsable, así como respecto de los cuatro ejes que integran el modelo de gestión de la RSU propuesto por Vallaeys et al (2009).

Las conclusiones obtenidas en este estudio, señalan que la mayoría de las IES adscritas en ambas iniciativas estudiadas no incluyen el término responsabilidad social o socialmente responsable en sus declaraciones de misión o visión. Asimismo, se observa una mayor presencia de elementos del concepto de RSU en las declaraciones de misión y visión relacionados con los ejes de formación y campus responsable.

\section{Revisión de la literatura}

De acuerdo con Larrán y Andrades (2015) el concepto de RSU está directamente relacionado con la Teoría de los stakeholders como el enfoque teórico más adecuado para delimitar conceptualmente a la RSU, a partir de la configuración de tres elementos esenciales y distintivos de su aplicación a las IES:

- Carácter voluntario, más allá del mero cumplimiento de la legislación vigente.

- Reformular la estrategia universitaria con un enfoque de gestión organizativa de mediano y largo plazo.

- Relación con los stakeholders de la universidad a través de un diálogo transparente y constante.

Estos aspectos característicos de la RSU identificados por Larrán y Andrades (2015) ponen énfasis en la gestión universitaria y la toma de decisiones implementadas con el propósito de que las IES fortalezcan la pertinencia de la misión universitaria respecto de las problemáticas y necesidades de sus partes interesadas y de la sociedad en su conjunto (Vallaeys et al, 2009; Gaete, 2016a; Gaete, 2015a).

En este contexto, adquiere especial relevancia que las IES que estén comprometidas con fortalecer su RSU incorporen los diferentes elementos y características distintivas del comportamiento socialmente responsable en su identidad corporativa, lo que de acuerdo con Gaete (2016b) implica incorporarlos en la declaración de misión, visión y valores institucionales, como un indicador importante del grado de institucionalización de la RSU en la gestión universitaria y por ende, en las demás funciones universitarias. 
Así, la RSU es una temática que ha logrado un crecimiento importante en gran parte de América Latina (AL) desde el año 2000 hasta nuestros días, con importantes formas de expresión en diferentes países de la Región (Martí y Martí-Vilar, 2013; Vallaeys y Álvarez, 2019), donde los primeros antecedentes contemporáneos del desarrollo de la RSU en AL se encuentran asociados con el proyecto Universidad Construye País (UCP), ejecutado en Chile entre los años 2001 y el 2008 (Muñoz, 2013).

Otras propuestas de redes de RSU son la Asociación Colombiana de Universidades (ASCUN) o el Observatorio Mexicano de Responsabilidad Social Universitaria (OMERSU), todas experiencias que describen solamente algunos de los ejemplos del desarrollo latinoamericano de la RSU en la actualidad (Londoño, 2013; Martí y Martí-Vilar, 2013; Arango et al, 2015; Escalante et al, 2016; Gaete, 2016a; Vallaeys y Álvarez, 2019). De esta manera, actualmente es posible observar en la literatura la existencia de dos redes interuniversitarias (Gaete, 2016a) que se están desarrollando con la participación de IES pertenecientes a diferentes países latinoamericanos, que cuentan con el potencial para expandir el concepto de RSU en la Región: URSULA Y AUSJAL.

\subsection{URSULA}

El día 16 de noviembre de 2016 se firma en Santiago de Chile la Declaración que crea la Unión de Responsabilidad Social Universitaria Latinoamericana (URSULA)², como un espacio para que diferentes actores públicos y privados reflexionen sobre el rol de la universidad en $\mathrm{AL}$, así como sobre las estrategias y metodologías más adecuadas para concretar dicho propósito en el mediano y largo plazo. El propósito fundamental de URSULA es crear una agenda y visión común sobre la RSU en $\mathrm{AL}$, desarrollando para ello una red conformada por universidades, organizaciones de la sociedad civil, gobiernos, empresas entre otras instituciones, que contribuyan al aprendizaje mutuo y la auto-reflexión sobre el comportamiento ético y solidario de cada entidad en su propio contexto territorial en el cual despliega su misión institucional, lo que permita retroalimentar el debate respecto del rol de las universidades en $\mathrm{AL}$.

Asimismo, en la Declaración de constitución de URSULA se destaca el hecho de que en la actualidad los diferentes procesos sociales exigen a las universidades mayor claridad en sus declaraciones de misión y visión, colocando a disposición de los directivos

\footnotetext{
2 Pude acceder mediante el enlace: http://unionursula.org/
} 
universitarios las orientaciones necesarias para liderar a sus instituciones hacia la excelencia y la pertinencia social, con la participación de los diferentes actores internos y externos de las universidades. En la Figura 1, se presenta un resumen con las principales consideraciones compartidas por las instituciones adheridas a URSULA.

Figura 1. Consideraciones compartidas en URSULA.

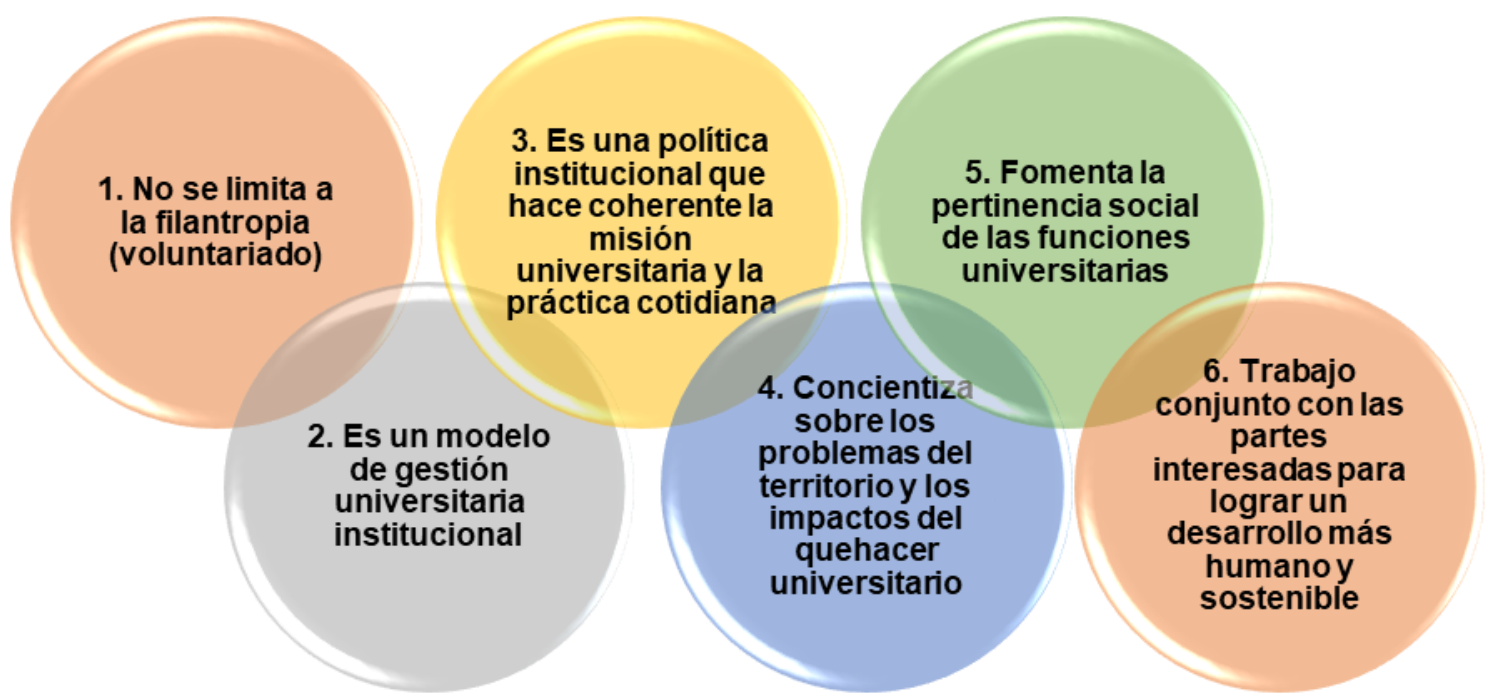

Fuente: Elaboración propia, basado en Declaración URSULA.

En la Figura 1, se identifican los seis elementos centrales de la filosofía de la responsabilidad social que forman parte de la declaración fundacional de URSULA, aspectos son propuestos a quienes decidan integrarse a dicha red.

Asimismo, actualmente URSULA se encuentra integrada por 72 instituciones iberoamericanas adheridas hasta el 04 de enero de 2018, entre las que se encuentran tanto IES como organizaciones públicas o privadas dedicadas a temáticas relacionadas con la educación superior o la responsabilidad social.

Según lo planteado en la Figura 2 más del $50 \%$ de las instituciones adheridas actualmente a URSULA provienen de Perú y Colombia, el 85\% del total provienen de Sudamérica y están distribuidas en 10 países, incluida la Organización No Gubernamental para el Desarrollo (ONGD) denominada "Transformando Futuros", institución española que coopera con Ecuador desde hace varios años en la promoción y difusión de iniciativas culturales, educativas y medioambientales que buscan la transformación social del país. 
Figura 2. Porcentaje de instituciones adheridas a URSULA por país (2018)

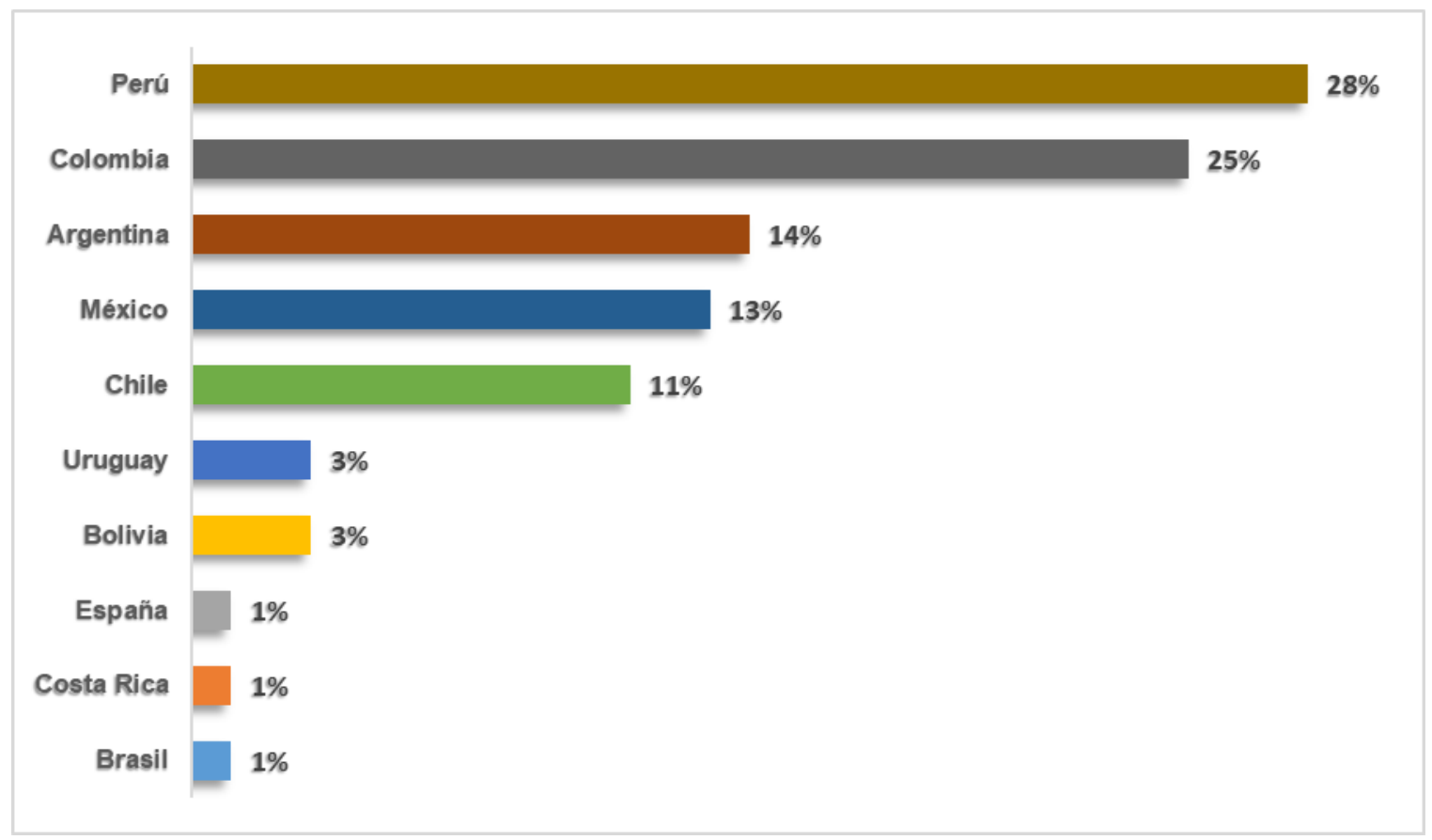

Fuente: Elaboración propia

Asimismo, URSULA ha organizado dos foros interinstitucionales hasta la fecha, el primero de ellos el año 2016 en la Universidad Tecnológica Metropolitana en Chile, con la participación de 40 universidades de 10 países de AL. El segundo Foro de URSULA se realizó el año 2017 en la ciudad de Medellín en Colombia, organizado por la Corporación Universitaria Minuto de Dios, la Universidad Cooperativa de Colombia y el Museo Casa de la Memoria.

\subsection{AUSJAL}

Otra red interuniversitaria latinoamericana que está generando importantes aportes a la RSU en la Región es la Asociación de Universidades Confiadas a la Compañía de Jesús en América Latina (AUSJAL) ${ }^{3}$, fue creada el 10 de noviembre de 1985 en Roma, actualmente es una red integrada por 31 universidades latinoamericanas confiadas a la Compañía de Jesús.

Según lo planteado en la Figura 3 , el $48 \%$ de las IES miembros de AUSJAL provienen de México y Brasil, el 51\% corresponde a países de Sudamérica, donde el total de 31 IES se distribuyen en 12 países latinoamericanos.

\footnotetext{
${ }^{3}$ Puede acceder mediante el enlace: http://www.ausjal.net/la-asociacion.html
} 
Figura 3. Porcentaje de instituciones adheridas a AUSJAL por país (2018)

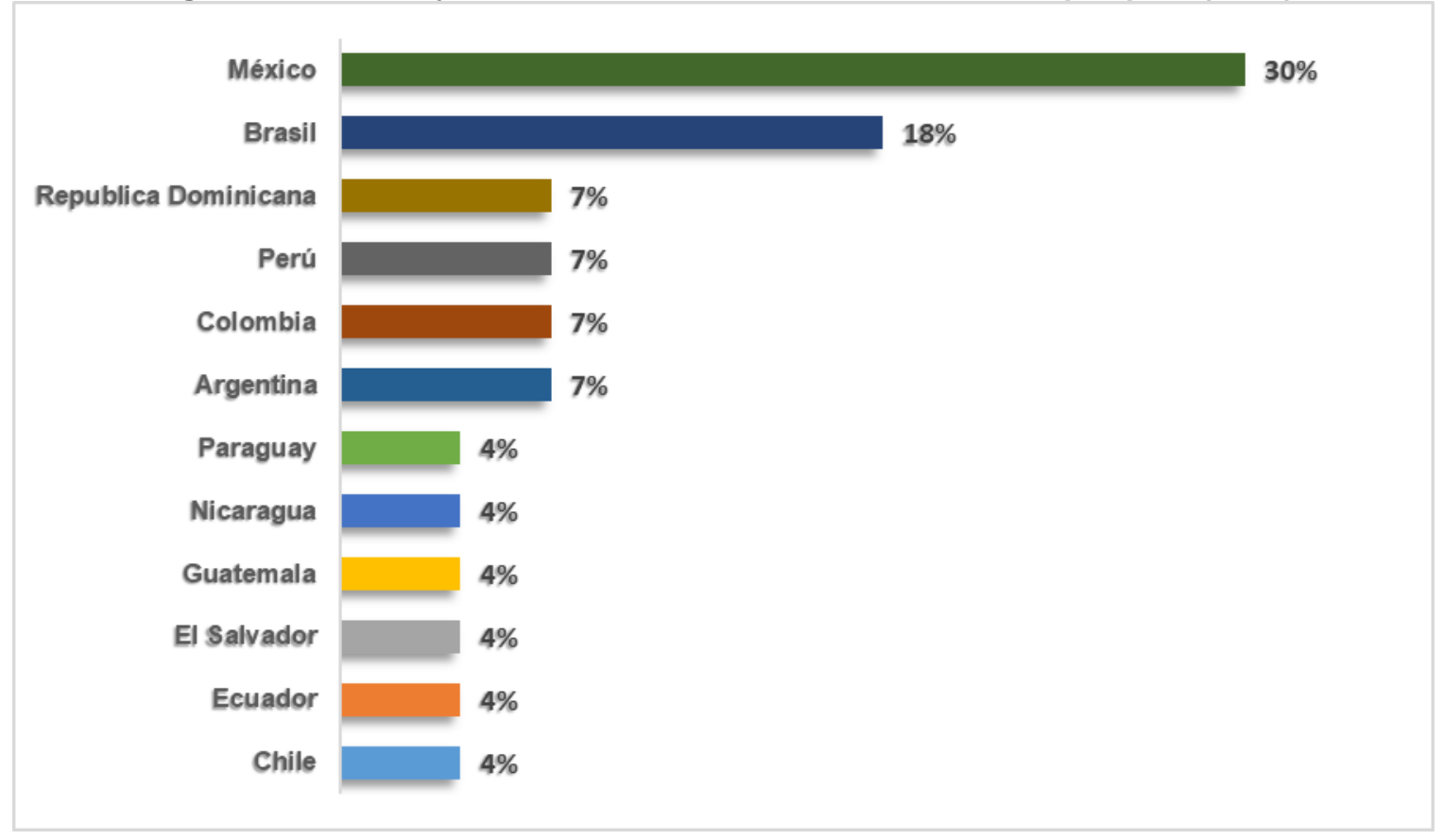

Fuente: Elaboración propia, 2018

Asimismo, desde el año 2007, se crea la red de homólogos RSU-AUSJAL integrada por 27 IES de 14 países latinoamericanos, donde México con 06 instituciones y Brasil con 04 instituciones respectivamente constituyen las aportaciones más numerosas a la red. Según Gargantini y Zaffaroni (2009, p. 18) la RSU en AUSJAL es concebida como:

La habilidad y efectividad de la universidad para responder a las necesidades de transformación de la sociedad donde está inmersa, mediante el ejercicio de sus funciones sustantivas: docencia, investigación, extensión y gestión interna. Estas funciones deben estar animadas por la búsqueda de la promoción de la justicia, la solidaridad y la equidad social, mediante la construcción de respuestas exitosas para atender los retos que implica promover el desarrollo humano sustentable.

A partir de la concepción de la RSU planteada por AUSJAL expuesta anteriormente, se desarrollan las políticas del comportamiento socialmente responsable de las universidades adscritas a esta red latinoamericana, lo que según Canelón (2013) ha sido recogido en loa Planes Estratégicos de AUSJAL desde el año 2001 en adelante, plasmadas en líneas de acción de la RSU de acuerdo a las características de cada universidad adherida a la red. Asimismo, Gargantini y Zaffaroni (2011) señalan que uno de los hitos más relevantes de la 
red de Homólogos RSU-AUSJAL es el desarrollo y aplicación de un Sistema de Autoevaluación y Gestión de la RSU de las IES miembros de AUSJAL.

En la Figura 4, se identifican los cuatro elementos centrales que integran el Sistema de Autoevaluación y Gestión de la RSU de AUSJAL, compuesto por cinco impactos del quehacer universitario: educativos, cognoscitivos y epistemológicos, sociales, ambientales y de funcionamiento organizacional. Para cada uno de los impactos antes señalados, se identifican un conjunto de políticas y sus respectivos indicadores que permiten a las IES adscritas a la red cuantificar los principales aspectos del funcionamiento institucional respecto de las cuales deben autoevaluar su RSU.

Figura 4. Elementos del Sistema de Autoevaluación y Gestión de la RSU de AUSJAL.

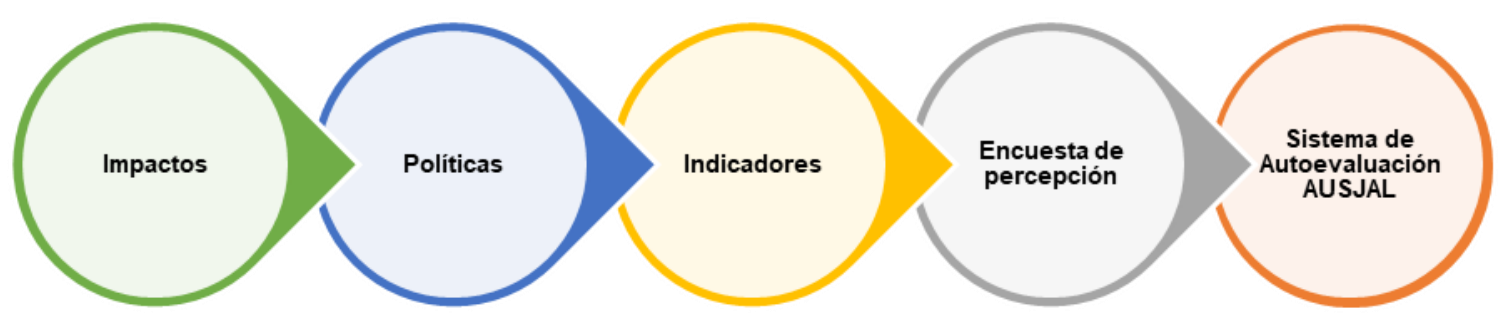

Fuente: Elaboración propia, 2018

Además, el sistema de autoevaluación de la RSU de AUSJAL tiene diseñado como instrumento de relevamiento de la información una encuesta de percepción que se aplica a los diferentes actores de la comunidad académica de cada IES.

\section{Metodología}

\subsection{Enfoque}

El presente estudio de carácter exploratorio-descriptivo-documental se desarrolla mediante un enfoque de investigación cuantitativo, considerando al análisis de contenido como técnica de recolección de la información. El objetivo principal de estudio es identificar la presencia del concepto de RSU en las declaraciones de misión y visión institucional de las IES pertenecientes a URSULA y AUSJAL. 


\subsection{Población de estudio}

La población de estudio son las IES adscritas a URSULA y AUSJAL, analizándose las declaraciones de misión y visión de las universidades que integran dichas redes interuniversitarias, considerando dos criterios de inclusión en la muestra: (1) ser una IES y (2) tener publicada en Internet su declaración de misión y visión entre el 01 de julio de 2017 hasta el día 05 de enero de 2018, período en el cual se realiza el estudio.

De acuerdo con los criterios de inclusión en la muestra contemplados en la metodología de este estudio, en el caso de URSULA se consideraron a 58 IES adscritas a dicha red pertenecientes a nueve países latinoamericanos, lo que representa el $81 \%$ del total de organizaciones integrantes de la misma, según la distribución presentada en la Tabla 1.

Tabla 1. Listado de IES adscritas a URSULA incluidas en el estudio (enero 2018).

\begin{tabular}{|c|c|c|c|}
\hline No. & País & IES & Simbología \\
\hline 1 & \multirow{5}{*}{ ARGENTINA } & Universidad Adventista del Plata & UAP \\
\hline 2 & & Universidad Católica de Salta & UCS \\
\hline 3 & & Universidad de Mendoza & UdM \\
\hline 4 & & Universidad Juan Agustín Maza & UJAM \\
\hline 5 & & Universidad Nacional de Catamarca & UNC \\
\hline 6 & \multirow{2}{*}{ BOLIVIA } & Universidad del Valle & UdV \\
\hline 7 & & Universidad Privada Franz Tamayo & UPFT \\
\hline 8 & BRASIL & Facultades Integradas de Taquara & FIT \\
\hline 9 & \multirow{7}{*}{ CHILE } & Universidad Austral de Chile & UACh \\
\hline 10 & & Universidad Autónoma de Chile & UA \\
\hline 11 & & Universidad Católica Silva Henríquez & $\mathrm{UCSH}$ \\
\hline 12 & & Universidad de Artes, Ciencias y Comunicación & UACyC \\
\hline 13 & & Universidad de Magallanes & UMAG \\
\hline 14 & & Universidad Pedro de Valdivia & UPV \\
\hline 15 & & Universidad Tecnológica Metropolitana & UTM \\
\hline 16 & \multirow{17}{*}{ COLOMBIA } & Corporación de Estudios Tecnológicos del Norte del Valle & CETNV \\
\hline 17 & & Corporación John F. Kennedy & CJFK \\
\hline 18 & & Corporación Universitaria Comfacauca & CUC \\
\hline 19 & & Corporación Universitaria Iberoamericana & CUI \\
\hline 20 & & Fundación de Estudios Superiores Comfanorte & FESC \\
\hline 21 & & Fundación Universitaria Católica del Norte & FUCN \\
\hline 22 & & Fundación Universitaria Católica Lumen Gentium & FUCLG \\
\hline 23 & & Institución Universitaria EAM & EAM \\
\hline 24 & & Institución Universitaria ITSA & ITSA \\
\hline 25 & & Universidad Católica de Oriente & UCO \\
\hline 26 & & Universidad Cooperativa de Colombia & UCC \\
\hline 27 & & Universidad del Quindío & UdQ \\
\hline 28 & & Universidad EAN & EAN \\
\hline 29 & & Universidad La Gran Colombia & ULGC \\
\hline 30 & & Universidad Pedagógica y Tecnológica de Colombia & UPyTC \\
\hline 31 & & Universidad Santiago de Cali & USC \\
\hline 32 & & Universitaria Virtual Internacional & UVI \\
\hline
\end{tabular}




\begin{tabular}{|c|c|c|c|}
\hline 33 & COSTA RICA & Universidad Estatal a Distancia & UNED \\
\hline 34 & \multirow{7}{*}{ MÉXICO } & $\begin{array}{l}\text { Centro de Formación Profesional de Chiapas, Maya. } \\
\text { Universidad Maya }\end{array}$ & UM \\
\hline 35 & & $\begin{array}{l}\text { Unidad profesional Interdisciplinaria de Ingeniería y } \\
\text { ciencias Sociales y Administrativas }\end{array}$ & UPIICSA \\
\hline 36 & & Universidad Autónoma de Baja California Sur & UABCS \\
\hline 37 & & Universidad de Quintana Roo & UQR \\
\hline 38 & & Universidad del Valle de Puebla & UVP \\
\hline 39 & & Universidad Michoacana de San Nicolás de Hidalgo & UMSNH \\
\hline 40 & & Universidad Tecnológica de Jalisco & UTJ \\
\hline 41 & \multirow{17}{*}{ PERÚ } & Universidad Científica del Sur & UCSur \\
\hline 42 & & Universidad Católica los Ángeles de Chimbote & UCACh \\
\hline 43 & & Universidad de Lima & $\mathrm{UL}$ \\
\hline 44 & & Universidad Latinoamericana CIMA & ULC \\
\hline 45 & & Universidad Nacional de Piura & UNP \\
\hline 46 & & Universidad Nacional de San Agustín de Arequipa & UNSAA \\
\hline 47 & & Universidad Nacional de San Cristóbal de Huamanga & UNSCH \\
\hline 48 & & Universidad Nacional del Santa & UNS \\
\hline 49 & & Universidad Nacional Federico Villareal & UNFV \\
\hline 50 & & Universidad Nacional Jorge Basadre Grohmann & UNJBG \\
\hline 51 & & Universidad Nacional Mayor de San Marcos & UNMSM \\
\hline 52 & & Universidad Nacional Santiago Antúnez de Mayolo & UNSAM \\
\hline 53 & & $\begin{array}{l}\text { Universidad Nacional Toribio Rodríguez de Mendoza de } \\
\text { Amazonas }\end{array}$ & UNTR \\
\hline 54 & & Universidad para el Desarrollo Andino & UDA \\
\hline 55 & & Universidad Privada Antenor Orrego & UPAO \\
\hline 56 & & Universidad Privada de Tacna & UPT \\
\hline 57 & & Universidad San Ignacio de Loyola & USIL \\
\hline 58 & URUGUAY & Universidad Católica del Uruguay & UCU \\
\hline
\end{tabular}

Fuente: Elaboración propia, 2018.

En la Tabla 2, se identifican las IES de AUSJAL analizadas en nuestro estudio, observándose que el 32\% provienen de México, donde el total de las instituciones analizadas se encuentra distribuido en 13 países de América Latina. 
Tabla 2. Listado de IES adscritas a AUSJAL incluidas en el estudio (enero 2018).

\begin{tabular}{|c|c|c|c|}
\hline No. & País & 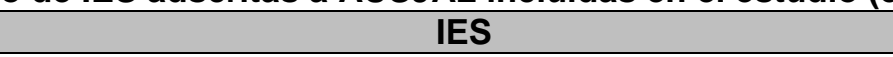 & Simbología \\
\hline 1 & Argentina & Universidad Católica de Córdoba & UCC \\
\hline 2 & \multirow{2}{*}{ Brasil } & Universidad Católica de Pernambuco & UNICAP \\
\hline 3 & & Faculdade Jesuita de Filosofía e Teología (Faje) & FAJE \\
\hline 4 & \multirow{2}{*}{ Colombia } & Pontificia Universidad Javeriana Bogotá & PUJB \\
\hline 5 & & Pontificia Universidad Javeriana Cali & PUJC \\
\hline 6 & Ecuador & Pontificia Universidad Católica del Ecuador & PUCE \\
\hline 7 & El Salvador & Universidad Centroamericana "José Simeón Cañas" & UCJSC \\
\hline 8 & Guatemala & Universidad Rafael Landívar & URL \\
\hline 9 & \multirow{7}{*}{ México } & Universidad Iberoamericana Torreón & UITorreón \\
\hline 10 & & Universidad Iberoamericana Ciudad de México & UICdM \\
\hline 11 & & Universidad Iberoamericana Puebla & UIP \\
\hline 12 & & Universidad Iberoamericana Tijuana & UITijuana \\
\hline 13 & & ITESO Universidad Jesuita de Guadalajara & ITESO \\
\hline 14 & & Universidad Loyola del Pacífico & ULP \\
\hline 15 & & ISIA-Instituto Superior Intercultural Ayuuk Oaxaca-Mixe & ISIA \\
\hline 16 & Nicaragua & Universidad Centroamericana & UC \\
\hline 17 & Paraguay & Instituto Superior de Estudios Humanísticos y Filosóficos & ISEHyF \\
\hline 18 & \multirow{2}{*}{ Perú } & Universidad del Pacífico & UP \\
\hline 19 & & Universidad Antonio Ruiz de Montoya & UARM \\
\hline 20 & $\begin{array}{c}\text { República } \\
\text { Dominicana }\end{array}$ & Instituto Especializado de Estudios Superiores Loyola & IEESL \\
\hline 21 & Uruguay & Universidad Católica del Uruguay & UCU \\
\hline 22 & Venezuela & Universidad Católica del Táchira & UCT \\
\hline
\end{tabular}

Fuente: elaboración propia, 2018

\subsection{Técnicas de recolección}

Se utiliza el análisis de contenido (AC) como técnica de recolección de la información habitualmente aplicada en diferentes campos de las Ciencias Sociales en los últimos años, para estudiar diversos documentos mediante la identificación de categorías de análisis (Larrán y López, 2010; Gaete, 2011; Canelón, 2013; Escalante et al, 2016; Gaete, 2015b; Gaete, 2016a).

El AC se aplicó a los planes estratégicos de las universidades identificadas previamente en las Tablas 1 y 2, para identificar los elementos y características más importantes del concepto de RSU en la identidad corporativa (Gaete, 2016b) de las IES iberoamericanas adscritas a ambas redes interuniversitarias.

La información fue recolectada mediante la elaboración de una base de datos ad hoc para la investigación con el apoyo del software Microsoft Excel, a través del cual se tabularon los datos con los cuales se elaboraron las tablas y figuras para integrar los resultados del estudio. 


\subsection{Procedimiento de análisis}

El procedimiento de análisis de los datos se desarrolló en dos fases: La primera, se realizó una búsqueda de las IES pertenecientes a URSULA y AUSJAL, con la finalidad de extraer la misión y visión de cada institución, considerando dos criterios de inclusión: (1) ser una IES y (2) tener publicada en Internet su declaración de misión y visión entre el 01 de julio de 2017 hasta el 05 de enero de 2018, período en el cual se realiza el estudio.

En la segunda fase, se aplicaron dos procedimientos de análisis de contenido: en primer lugar, se identificó dentro de las declaraciones de misión y visión la presencia de los términos "responsabilidad social" o "socialmente responsable". En segundo lugar, se identificaron las temáticas consideradas en cada uno de los ejes de la RSU propuestos por Vallaeys et al (2009) señalados en la Figura 5.

El análisis descrito anteriormente consistió en una búsqueda individual dentro de la redacción de la misión y visión de las IES incluidas en el estudio, identificando aquellas frases que contengan los aspectos relacionados con el concepto de RSU. 
Figura 5. Ejes y sub-ejes del Modelo de RSU.
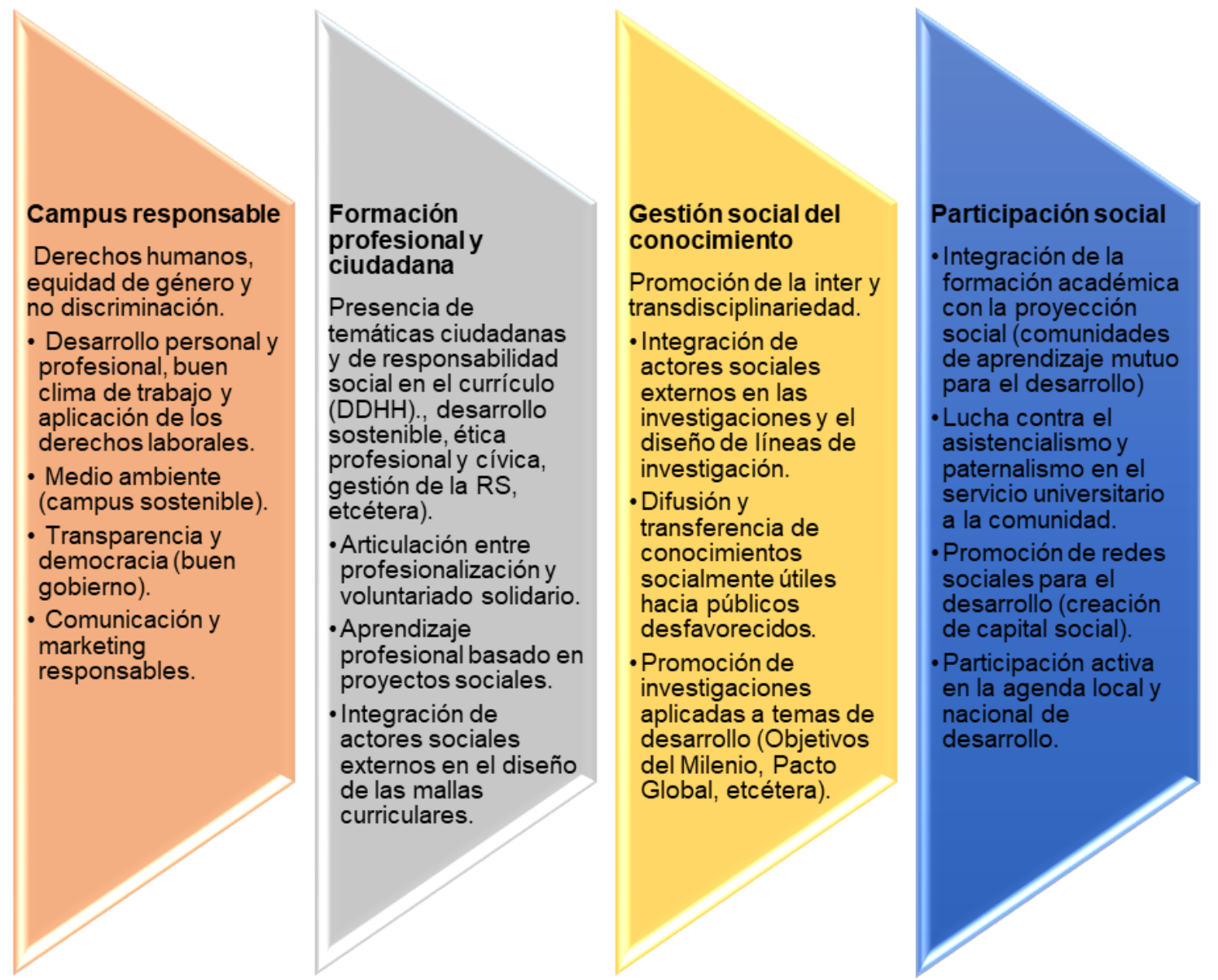

Fuente: Elaboración propia, basado en Vallaeys et al (2009).

De acuerdo con los autores del modelo de RSU descrito anteriormente en la Figura 5, dicha propuesta se estructura sobre la base de dos grandes orientaciones para identificar los ejes de la misma: una que incluye los aspectos esenciales propios del quehacer universitario (Formación Profesional y Gestión Social del Conocimiento) y otra que incluye los aspectos tradicionales de la responsabilidad social corporativa (Campus Responsable y Participación Social).

\section{Resultados}

\subsection{El caso de URSULA}

A partir de lo señalado en la Tabla 1, Colombia y Perú son los países que aportan más IES a la muestra de nuestro estudio con 17 cada uno. Asimismo, la distribución geográfica del total de las IES de URSULA pertenece mayoritariamente a Sudamérica como ámbito de mayor influencia de URSULA, con excepción de las que provienen de Costa Rica y México. 
4.1.1 Presencia de los términos "responsabilidad social" o "socialmente responsable".

En este primer análisis, se revisaron las declaraciones de misión y visión institucional con el propósito de identificar mediante la técnica de análisis de contenido la inclusión del término responsabilidad social o socialmente responsable de ambas declaraciones institucionales, como expresión el compromiso estratégico de las universidades con la RSU. En este caso, según se observa en la Figura 6, la inclusión de los términos analizados en la declaración de misión institucional está presente en el $26 \%$ de las 58 universidades incluidas en la población de estudio, mientras que únicamente el $14 \%$ de las IES de la muestra incluye los términos "responsabilidad social" o "socialmente responsable" en su declaración de visión institucional.

Figura 6. Numero de IES de URSULA que incluyen el término responsabilidad social o socialmente responsable en su declaración de misión y visión institucional, (enero 2018).

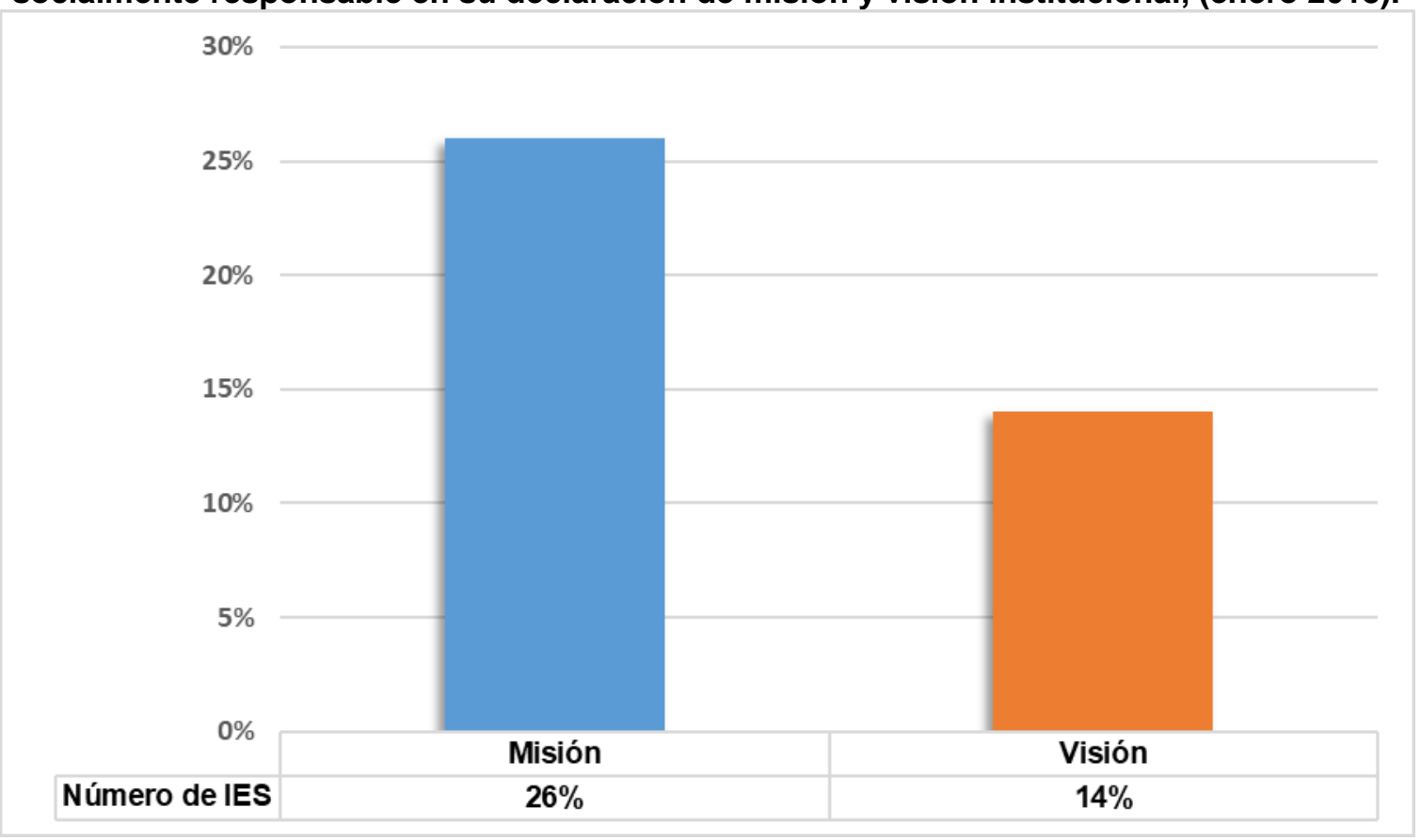

Fuente: Elaboración propia, 2018

Según lo expuesto en la Figura 6, la baja cantidad de IES que incluyen los términos "responsabilidad social" o "socialmente responsable" en sus declaraciones de misión y visión, puede ser interpretado como la ausencia del comportamiento socialmente responsable en la filosofía estratégica de cada institución, tanto en lo relativo a su razón de ser expuesta en la misión institucional, así como en su aspiración o deseabilidad a alcanzar en el mediano y largo plazo en la mayoría de las instituciones que integran URSULA. Lo anterior, es un 
hallazgo interesante desde la perspectiva de lo señalado en la Declaración fundacional de URSULA, que establece la importancia que posee para dicha red la claridad de las declaraciones de misión y visión como un aspecto orientador para los directivos universitarios de las IES que están adheridas.

A partir de los resultados obtenidos para el caso de URSULA, la única IES perteneciente a esta red que incluye ambos términos analizados tanto en su declaración de misión como de visión es la Universidad Nacional de Piura (UNP) en Perú.

\subsubsection{Presencia de los ejes de la RSU}

En la Figura 7, se presentan los resultados generales obtenidos para los cuatro ejes de la RSU, destacando los aspectos relacionados con la formación profesional en las declaraciones de misión institucional de las IES pertenecientes a URSULA.

Figura 7. Número de IES de URSULA que incluyen los ejes de la RSU incluidos en la declaración de misión y visión, (2018).

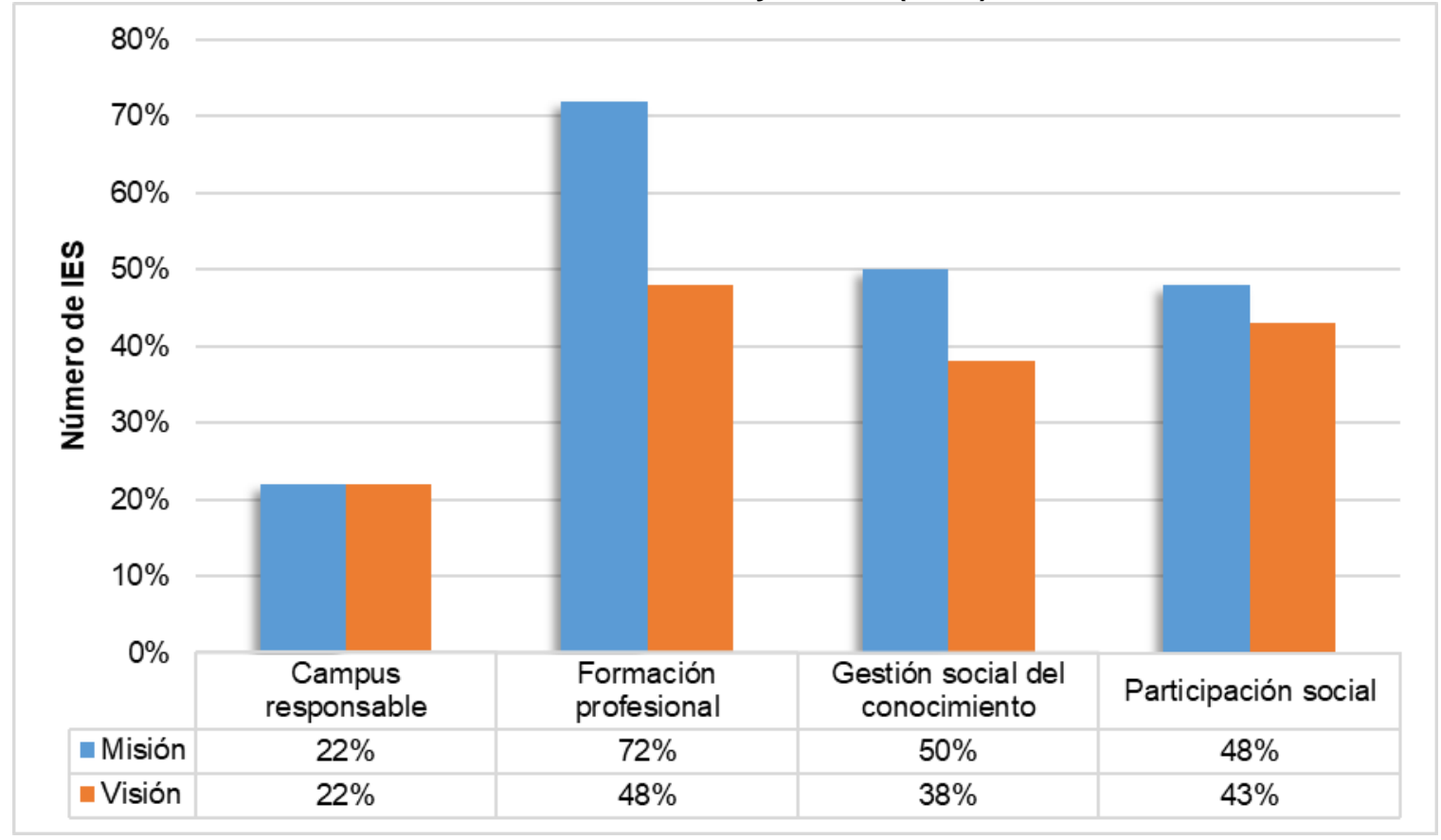

Fuente: Elaboración propia.

A partir de lo expuesto anteriormente en Figura 7, el 22\% de las IES de URSULA incluyen elementos de Campus Responsable en sus declaraciones de misión y visión institucional, por debajo de lo observado en los otros tres ejes del modelo de RSU propuesto por Vallaeys et al (2009). Además, los ejes de Formación Profesional y Gestión Social del 
Conocimiento que corresponden a las funciones tradicionales y distintivas de las IES son los que registran los mejores resultados en el estudio, lo que puede ser interpretado como un aspecto positivo en cuanto a la incorporación de los aspectos esenciales de la RSU en ambas funciones distintivas de cualquier IES.

De igual forma, a continuación en la Tabla 3 se presenta la distribución de IES pertenecientes a URSULA de acuerdo con la presencia de los ejes y sub-ejes propuestos por Vallaeys et (2009) en las declaraciones de misión y visión de dichas instituciones.

Tabla 3. Distribución de IES de URSULA según Ejes y Sub-ejes de la RSU.

\begin{tabular}{|c|c|c|c|}
\hline & Temática & Misión & Visión \\
\hline \multirow{5}{*}{ 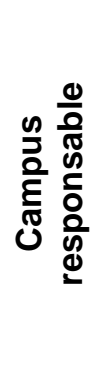 } & 1. Derechos humanos, equidad de género y no discriminación. & $16 \%$ & $17 \%$ \\
\hline & $\begin{array}{l}\text { 2. Desarrollo personal y profesional, buen clima de trabajo y } \\
\text { aplicación de los derechos laborales. }\end{array}$ & $2 \%$ & $2 \%$ \\
\hline & 3. Medio ambiente (campus sostenible). & $2 \%$ & $3 \%$ \\
\hline & $\begin{array}{l}\text { 4. Transparencia y democracia (buen gobierno) han integrado la } \\
\text { responsabilidad social. }\end{array}$ & $3 \%$ & $5 \%$ \\
\hline & 5. Comunicación y marketing responsables. & $0 \%$ & $0 \%$ \\
\hline \multirow{4}{*}{ 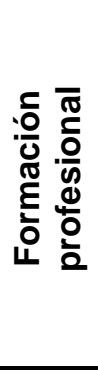 } & $\begin{array}{l}\text { 1. Presencia de temáticas ciudadanas y de responsabilidad social } \\
\text { en el currículo (derechos humanos), desarrollo sostenible, ética } \\
\text { profesional y cívica, gestión de la RS, etcétera). }\end{array}$ & $62 \%$ & $43 \%$ \\
\hline & 2. Articulación entre profesionalización y voluntariado solidario. & $12 \%$ & $9 \%$ \\
\hline & 3. Aprendizaje profesional basado en proyectos sociales. & $3 \%$ & $2 \%$ \\
\hline & $\begin{array}{l}\text { 4. Integración de actores sociales externos en el diseño de las } \\
\text { mallas curriculares. }\end{array}$ & $5 \%$ & $2 \%$ \\
\hline \multirow{4}{*}{ 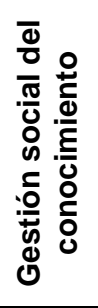 } & 1. Promoción de la inter y transdisciplinariedad. & $2 \%$ & $0 \%$ \\
\hline & $\begin{array}{l}\text { 2. Integración de actores sociales externos en las investigaciones y } \\
\text { el diseño de líneas de investigación. }\end{array}$ & $12 \%$ & $10 \%$ \\
\hline & $\begin{array}{l}\text { 3. Difusión y transferencia de conocimientos socialmente útiles } \\
\text { hacia públicos desfavorecidos. }\end{array}$ & $26 \%$ & $12 \%$ \\
\hline & $\begin{array}{l}\text { 4. Promoción de investigaciones aplicadas a temas de desarrollo } \\
\text { (Objetivos del Milenio, Pacto Global, etcétera). }\end{array}$ & $31 \%$ & $29 \%$ \\
\hline \multirow{4}{*}{ 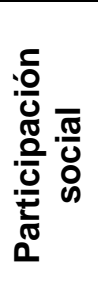 } & $\begin{array}{l}\text { 1. Integración de la formación académica con la proyección social } \\
\text { (comunidades de aprendizaje mutuo para el desarrollo) }\end{array}$ & $0 \%$ & $0 \%$ \\
\hline & $\begin{array}{l}\text { 2. Lucha contra el asistencialismo y paternalismo en el servicio } \\
\text { universitario a la comunidad. }\end{array}$ & $0 \%$ & $0 \%$ \\
\hline & $\begin{array}{l}\text { 3. Promoción de redes sociales para el desarrollo (creación de } \\
\text { capital social). }\end{array}$ & $17 \%$ & $12 \%$ \\
\hline & 4. Participación activa en la agenda local y nacional de desarrollo. & $41 \%$ & $38 \%$ \\
\hline
\end{tabular}

Fuente: elaboración propia. 


\subsubsection{Campus Responsable}

En el caso de URSULA, se observa una escasa presencia de los sub-ejes contenidos en el Campus Responsable, donde únicamente se observa que el $16 \%$ de las declaraciones de misión y el $17 \%$ de las declaraciones de misión incluyen aspectos relacionados con el sub-eje 1.

Lo anterior, puede deberse a que dichos aspectos provienen del concepto de responsabilidad social corporativa y no son tan habituales dentro del quehacer universitario más tradicional, lo que plantea un desafío importante para las IES que integran URSULA implementen acciones y estrategias de fortalecimiento de dichos aspectos, como expresión de un compromiso más explícito con este eje de la RSU planteado en el modelo de Vallaeys et al (2009).

\subsubsection{Formación Profesional}

Este segundo eje del modelo de RSU es ampliamente considerado en las declaraciones de misión y visión de las IES de URSULA, destacando los resultados obtenidos en el sub-eje 1 relativo a la presencia de temáticas ciudadanas y de responsabilidad social en el currículo, incluida en el $62 \%$ de las declaraciones de misión y el $43 \%$ de las declaraciones de visión institucional.

A nivel individual, destaca la Universidad de Quintana Roo (UQR) en México que incluye tres de los sub-ejes de la Formación Profesional en la Misión institucional, mientras que en la declaración de visión institucional de las IES adscritas a URSULA, destaca la Universidad Michoacana de San Nicolás de Hidalgo (UMSNH) también de México, quien incluye tres sub-ejes. En el caso de esta última institución, además incluye dos de los subejes de la Formación Profesional en su declaración misión, evidenciado un planteamiento estratégico más coherente respecto de lo analizado en este estudio, incluyendo estos aspectos tanto en su razón de ser como en sus aspiraciones futuras.

\subsubsection{Gestión Social del Conocimiento}

El tercer eje del modelo de RSU analizado se encuentra relacionado con otra de las funciones esenciales de las IES como es la investigación científica, destacando el sub-eje Promoción de investigaciones aplicadas a temas de desarrollo, donde el $30 \%$ de las IES de AUSJAL incluye este aspecto en sus declaraciones de misión y visión institucional. 
Además, la Universidad Austral de Chile (UACH) y la Universidad Michoacana de San Nicolás de Hidalgo (UMSNH) de México son las IES que más incluyen aspectos de este eje en la misión institucional, con tres sub-ejes cada una. En lo que se refiere a la declaración de visión institucional, destacan los casos de las IES mexicanas Universidad de Quintana Roo (UQR) y la Universidad Michoacana de San Nicolás de Hidalgo (UMSNH), con tres sub-ejes cada una.

\subsubsection{Participación social}

En el último eje del Modelo de RSU de Vallaeys et al (2009), solo se registraron resultados en dos de los sub-ejes asociados a esta temática, siendo especialmente destacado lo relativo a la participación activa en la agenda local y nacional de desarrollo, aspecto que está presente en el $41 \%$ de las declaraciones de misión y el 38\% para lo relativo a la declaración de visión en las IES de URSULA.

\subsection{El caso de AUSJAL}

En este segundo caso de estudio, según lo indicado en los criterios de selección de la muestra expuestos en la metodología, se consideraron a 22 IES que mantienen publicada online su declaración de misión y visión, representando el $71 \%$ del total de integrantes de AUSJAL, que actualmente se encuentra integrada por 31 instituciones.

4.2.1 Presencia de los términos "responsabilidad social" o "socialmente responsable".

Los resultados obtenidos de este análisis se presentan en la Figura 8, donde tan solo el $9 \%$ de las IES adscritas a AUSJAL incluyen en su misión institucional los términos analizados, mientras que el 14\% lo incorpora en la declaración de visión institucional. 
Figura 8. Número de IES de AUSJAL que incluyen el término responsabilidad social o socialmente responsable en su declaración de misión y visión institucional (2018)

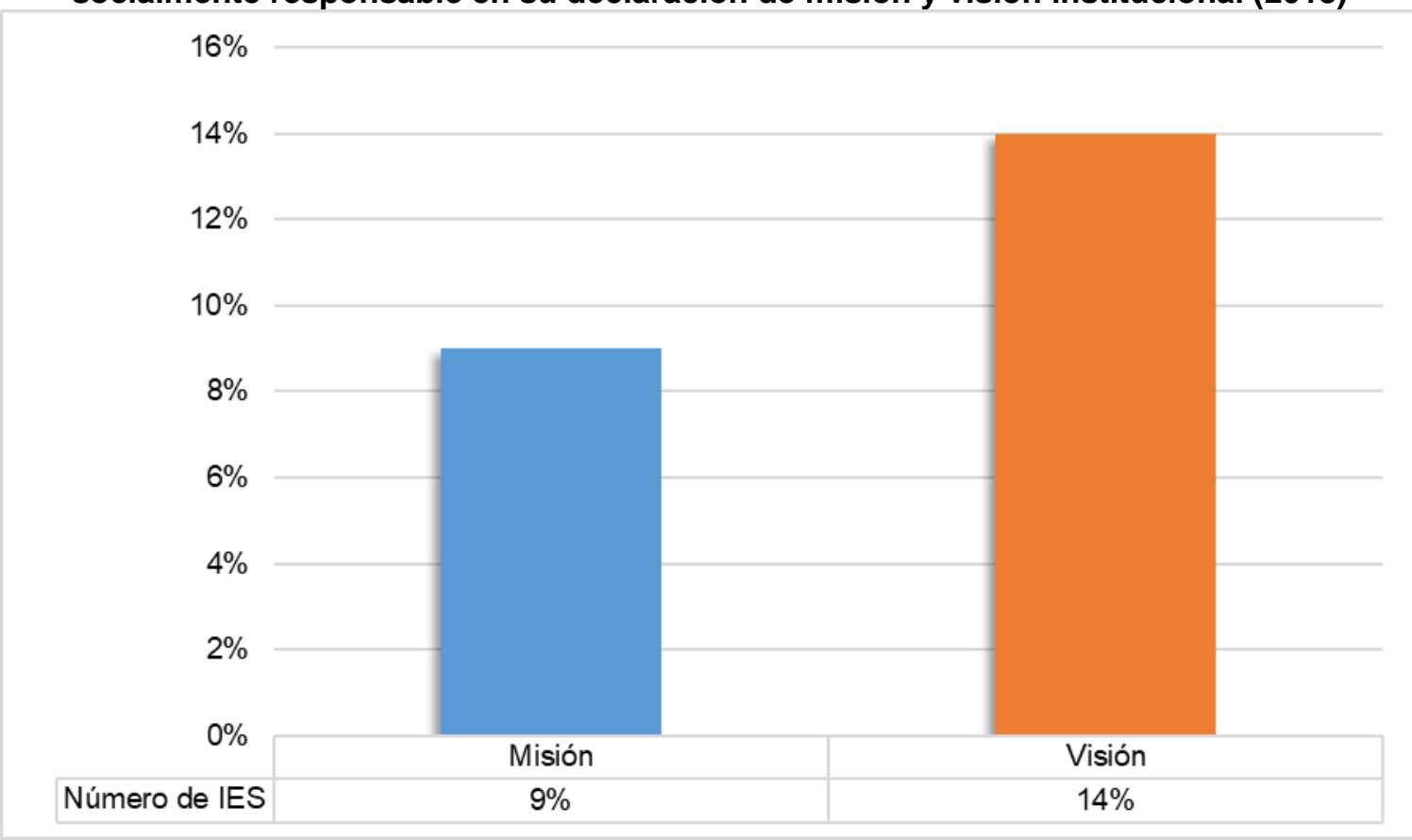

Fuente: Elaboración propia.

De acuerdo con la Figura 8, la única IES de AUSJAL que registró ambos términos analizados tanto en su declaración de misión y visión es la Pontificia Universidad Javeriana de Cali (PUJC) en Colombia, observándose un desafío importante para que las IES de esta red interuniversitaria expliciten en su razón de ser y en sus aspiraciones de desarrollo estratégico este tipo de conceptos, que si bien no son garantía de un efectivo comportamiento socialmente responsable, se transforman en una expresión clara del compromiso que cada institución asumirá con la RSU.

\subsubsection{Presencia de los ejes de la RSU.}

En la Figura 9, se observan los resultados generales obtenidos del análisis de las declaraciones de misión y visión de las IES pertenecientes a AUSJAL. Los sub-ejes de la Formación profesional son los que obtienen los mejores resultados en ambos elementos analizados en los planes estratégicos de cada institución, observándose una presencia más homogénea en los otros tres ejes de la RSU analizados en el estudio, tanto para la misión como la visión. 
Figura 9. Número de IES de URSULA que incluyen los ejes de la RSU incluidos en la declaración de misión y visión de las IES de AUSJAL (2018)

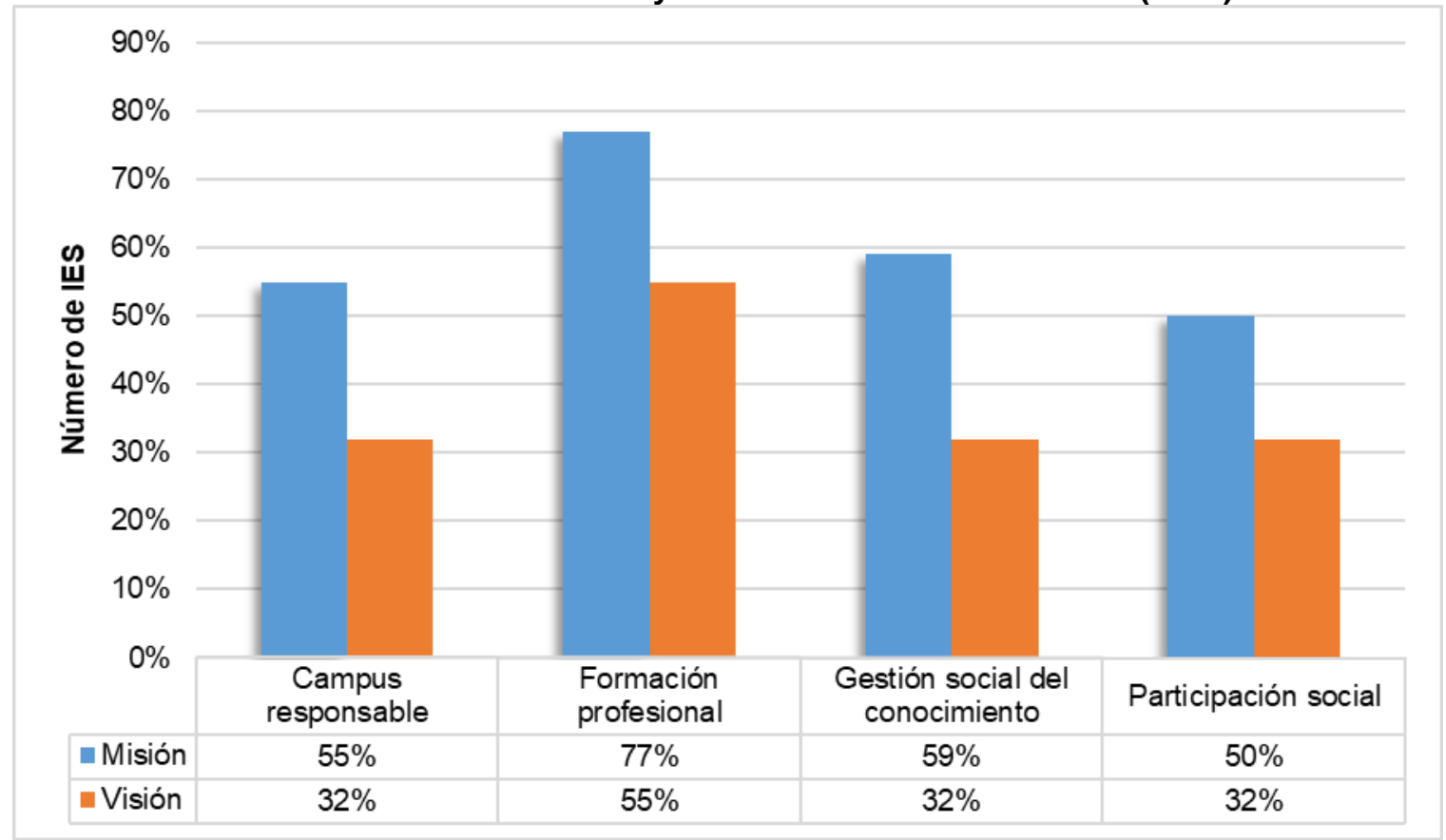

Fuente: Elaboración propia.

En la Tabla 4, se presenta la distribución de las IES de AUSJAL según la presencia de los ejes y sub-ejes de la RSU en las declaraciones de misión y visión, destacándose la presencia de temáticas ciudadanas y de responsabilidad social en el currículo en las declaraciones de Misión y Visión con el 64\% y 55\% de las IES respectivamente, como un sub-eje de la Formación Profesional dentro del modelo de la RSU propuesto por Vallaeys et al (2009). 
Tabla 4. Distribución de IES de AUSJAL según Ejes y Sub-ejes de la RSU.

\begin{tabular}{|c|c|c|c|}
\hline & Temática & Misión & Visión \\
\hline \multirow{5}{*}{ 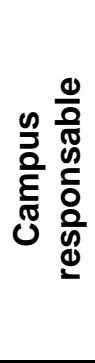 } & 1. Derechos humanos, equidad de género y no discriminación. & $36 \%$ & $14 \%$ \\
\hline & $\begin{array}{l}\text { 2. Desarrollo personal y profesional, buen clima de trabajo y } \\
\text { aplicación de los derechos laborales. }\end{array}$ & $23 \%$ & $18 \%$ \\
\hline & 3. Medio ambiente (campus sostenible). & $0 \%$ & $5 \%$ \\
\hline & $\begin{array}{l}\text { 4. Transparencia y democracia (buen gobierno). han integrado la } \\
\text { responsabilidad social. }\end{array}$ & $14 \%$ & $5 \%$ \\
\hline & 5. Comunicación y marketing responsables. & $0 \%$ & $0 \%$ \\
\hline \multirow{4}{*}{ 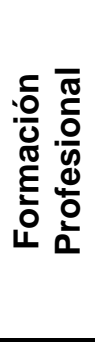 } & $\begin{array}{l}\text { 1. Presencia de temáticas ciudadanas y de responsabilidad social en } \\
\text { el currículo (derechos humanos), desarrollo sostenible, ética } \\
\text { profesional y cívica, gestión de la RS, etcétera). }\end{array}$ & $64 \%$ & $55 \%$ \\
\hline & 2. Articulación entre profesionalización y voluntariado solidario. & $27 \%$ & $5 \%$ \\
\hline & 3. Aprendizaje profesional basado en proyectos sociales. & $18 \%$ & $5 \%$ \\
\hline & $\begin{array}{l}\text { 4. Integración de actores sociales externos en el diseño de las } \\
\text { mallas curriculares. }\end{array}$ & $0 \%$ & $0 \%$ \\
\hline \multirow{4}{*}{ 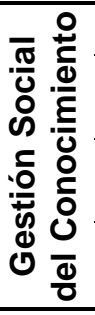 } & 1. Promoción de la inter y transdisciplinariedad. & $9 \%$ & $5 \%$ \\
\hline & $\begin{array}{l}\text { 2. Integración de actores sociales externos en las investigaciones y } \\
\text { el diseño de líneas de investigación. }\end{array}$ & $18 \%$ & $5 \%$ \\
\hline & $\begin{array}{l}\text { 3. Difusión y transferencia de conocimientos socialmente útiles hacia } \\
\text { públicos desfavorecidos. }\end{array}$ & $32 \%$ & $32 \%$ \\
\hline & $\begin{array}{l}\text { 4. Promoción de investigaciones aplicadas a temas de desarrollo } \\
\text { (Objetivos del Milenio, Pacto Global, etcétera). }\end{array}$ & $50 \%$ & $27 \%$ \\
\hline \multirow{4}{*}{ 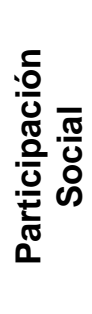 } & $\begin{array}{l}\text { 1. Integración de la formación académica con la proyección social } \\
\text { (comunidades de aprendizaje mutuo para el desarrollo) }\end{array}$ & $0 \%$ & $0 \%$ \\
\hline & $\begin{array}{l}\text { 2. Lucha contra el asistencialismo y paternalismo en el servicio } \\
\text { universitario a la comunidad. }\end{array}$ & $32 \%$ & $27 \%$ \\
\hline & $\begin{array}{l}\text { 3. Promoción de redes sociales para el desarrollo (creación de } \\
\text { capital social). }\end{array}$ & $9 \%$ & $14 \%$ \\
\hline & 4. Participación activa en la agenda local y nacional de desarrollo. & $50 \%$ & $32 \%$ \\
\hline
\end{tabular}

Fuente: elaboración propia.

Según lo planteado en la Tabla 4, el eje de Gestión Social del Conocimiento es el único de los cuatro ejes considerados en el modelo de RSU de Vallaeys et al (2009) en donde existe a lo menos una IES que incluye alguno de los sub-ejes de este aspecto en su declaración de misión o visión.

\subsubsection{Campus responsable}

En lo que se refiere a este eje, a nivel de la declaración de Misión Institucional se destaca la incorporación de los derechos humanos, equidad de género y no discriminación como un aspecto importante para el $36 \%$ de las IES de AUSJAL, mientras que a nivel 
individual la Universidad Centroamericana "José Simeón Cañas" (UCJSC) de El Salvador, que incluye el $60 \%$ de los sub-ejes en su declaración de Visión institucional.

\subsubsection{Formación profesional}

En el segundo eje la RSU es el que registra los mejores resultados para el caso de AUSJAL, destacando lo observado respecto de la presencia de temáticas ciudadanas y de responsabilidad social en el currículo, que alcanza el 64\% en la misión y el 55\% en la visión.

A nivel individual, la Universidad Católica de Córdoba (UCC) de Argentina registra un $75 \%$ de los sub-ejes de la Formación Profesional, como una de las IES que más incorporan aspectos relacionados con dicha temática.

\subsubsection{Gestión social del conocimiento}

En este tercer eje destaca que el $50 \%$ de las IES de AUSJAL incluyen en sus declaraciones de misión institucional aspectos relacionados con la promoción de investigaciones aplicadas a temas de desarrollo.

También es posible destacar el caso de la Pontificia Universidad Católica del Ecuador (PUCE), que incluye en su declaración de misión a los cuatro sub-ejes de la gestión social del conocimiento contemplado en el modelo de RSU utilizado en nuestra investigación. También, destaca en este tercer eje lo relativo a la Universidad Centroamericana "José Simeón Cañas" (UCJSC), IES que incluye en su declaración de visión los cuatro sub-ejes considerados por Vallaeys et al (2009) en su modelo de RSU.

Ambas situaciones señaladas anteriormente son únicas para el caso de la AUSJAL analizado en nuestro artículo, debido a que en ninguno de los otros tres ejes del modelo de RSU se presenta esta situación de lograr el 100\% de los sub-ejes.

\subsubsection{Participación social}

Para el caso de AUSJAL, se trata del aspecto que las IES menos incorporan en su redacción las declaraciones de misión y visión, especialmente en el sub-eje relacionado con la integración de la formación académica con la proyección social hacia la comunidad, como se planteó anteriormente en la Tabla 4, exceptuando lo relativo a la participación activa en la agenda local y nacional de desarrollo, que está incluida en el 50\% de las declaraciones de misión de las IES de AUSJAL. 
Finalmente, en la Tabla 5 se desarrolla una comparación de las IES pertenecientes tanto URSULA como de AUSJAL, que fueron destacadas previamente en el análisis de la presencia de cada uno de los ejes del modelo de RSU de Vallaeys et al (2009) en sus declaraciones de Misión y Visión institucional.

Tabla 5. Comparación IES de URSULA y AUSJAL que más incluyen a la RSU en su declaración de Misión y Visión institucional.

\begin{tabular}{|c|c|c|c|c|c|c|c|c|c|c|c|}
\hline & \multirow{2}{*}{ Universidad } & \multicolumn{5}{|c|}{ Misión } & \multicolumn{5}{|c|}{ Visión } \\
\hline & & CR & FPC & GSC & PS & Total & CR & FPC & GSC & PS & Total \\
\hline \multirow{3}{*}{ 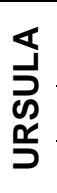 } & $\begin{array}{l}\text { Universidad Michoacana de San } \\
\text { Nicolás de Hidalgo (UMSNH) }\end{array}$ & 0 & 2 & 3 & 2 & 7 & 0 & 3 & 3 & 2 & 8 \\
\hline & Universidad de Quintana Roo (UQR) & 1 & 3 & 2 & 2 & 8 & 0 & 0 & 3 & 1 & 4 \\
\hline & Universidad Austral de Chile (UACh) & 0 & 1 & 3 & 2 & 6 & 1 & 1 & 0 & 0 & 2 \\
\hline \multirow{4}{*}{ 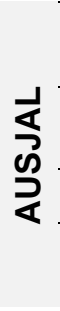 } & $\begin{array}{l}\text { Universidad Centroamericana "José } \\
\text { Simeón Cañas" (UCJSC) }\end{array}$ & 2 & 1 & 1 & 2 & 6 & 3 & 2 & 4 & 3 & 12 \\
\hline & $\begin{array}{l}\text { Universidad Católica de Córdoba } \\
\text { (UCC) }\end{array}$ & 1 & 3 & 3 & 3 & 10 & 2 & 2 & 1 & 2 & 7 \\
\hline & P. Univ. Católica del Ecuador (PUCE) & 3 & 3 & 4 & 0 & 10 & 1 & 0 & 0 & 0 & 1 \\
\hline & $\begin{array}{l}\text { Universidad Iberoamericana d } \\
\text { Ciudad de México (UICdM) }\end{array}$ & 1 & 1 & 2 & 2 & 6 & 0 & 1 & 2 & 3 & 6 \\
\hline
\end{tabular}

Fuente: elaboración propia $(\mathrm{RS} / \mathrm{SR}=$ responsabilidad social/socialmente responsable; $\mathrm{CR}=\mathrm{Campus}$ responsable; FPC=Formación profesional y ciudadana; GSC=Gestión social del conocimiento; PS=Participación social).

Así, es posible observar que la Universidad Centroamericana “José Simeón Cañas" de El Salvador es la IES que incorpora más claramente cada uno de los ejes del modelo de RSU estudiado, especialmente en la declaración de visión institucional con el $71 \%$ del total de los sub-ejes. Lo anterior, puede ser interpretado como una aspiración o deseo de avanzar hacia un mejor comportamiento socialmente responsable de la institución en el futuro.

En cambio, la Universidad Católica de Córdoba y la Pontificia Universidad Católica del Ecuador incorporan el 59\% los sub-ejes de la RSU en su declaración de Misión institucional, es decir, en su razón de ser actual y por ende debieran estar implementando acciones que reflejen dicha orientación en su diario quehacer institucional como una realidad claramente observable.

\section{Conclusiones}

A partir de los resultados exhibidos en el presente trabajo, se observa una baja presencia de los diferentes aspectos del concepto de RSU en las declaraciones de visión y misión consideradas en nuestro estudio, a pesar de que ha transcurrido más de una década 
de la instalación de dicho modelo en las IES de América Latina (Martí y Martí-Vilar, 2013). Además, se trata de IES que pertenecen a redes interuniversitarias que desarrollan acciones concretas para fortalecer el comportamiento socialmente responsable en los sistemas universitarios latinoamericanos, por ende debiera ser una prioridad institucional que esté expresada claramente en su identidad corporativa (Gaete, 2016b), como parte de un discurso explícito dentro de los planes estratégicos institucionales como instrumentos de gestión en donde se fijan las prioridades y propósitos fundamentales del funcionamiento de mediano y largo plazo de cada IES, así como los recursos económicos utilizados en su quehacer institucional.

Lo anterior, se relaciona directamente con la respuesta a nuestra pregunta de investigación $\mathrm{N}^{\circ} 1$, en cuenta a la muy baja frecuencia que tiene el uso del término responsabilidad social/ socialmente responsable en las declaraciones de misión y visión institucional analizadas en nuestra muestra, como se observa en las Figuras 6 y 8 , ratificado además por lo expuesto en la Tabla 5, donde se evidencia que únicamente dos universidades de la muestra incluyen dichos términos en ambas declaraciones estratégicas institucionales analizadas.

Si bien es cierto, la inclusión de dichos términos en la redacción de la misión y visión institucional pueda ser considerado como algo meramente decorativo o un aspecto insuficiente como real expresión de un comportamiento más socialmente responsable, también pueden explicitar el grado de compromiso que cada IES asume en cuanto a la construcción de una cultura organizacional caracterizada por dicho modelo de gestión, por lo que incluirlo en este tipo de declaraciones que forman parte de la identidad corporativa a nuestro juicio puede contribuir a la instalación de un discurso cultural más socialmente responsable entre sus miembros.

Asimismo, nuestro estudio a través de la pregunta de investigación №2 proponía un segundo análisis de contenido de las declaraciones de misión y visión institucional, relativa a la presencia de los aspectos distintivos del concepto de RSU.

De esta manera, los resultados obtenidos confirman que los elementos relacionados con la Formación Profesional y Ciudadana están incorporados en las declaraciones de misión y visión, como se observa en los Gráficos 4 y 6 respectivamente, lo que es coherente con la principal razón de ser de todas las IES incluidas en el estudio, ratificado con los resultados expuestos en la Tabla 5 donde se establece que es en la declaración de Misión institucional en donde habitualmente están presente los ejes de la RSU. 
De acuerdo con el modelo de RSU de Vallaeys el at. (2009) analizado en nuestra investigación, resulta previsible que existan mayores evidencias de los ejes de Formación Profesional y Ciudadana así como de la Gestión Social del Conocimiento, por tratarse de aspectos distintivos de las funciones misionales de una IES en cualquier lugar del mundo, lo que se ratifica en nuestro estudio especialmente para la declaración de misión institucional. Por otra parte, los resultados obtenidos para los ejes de Campus Responsable y Participación Social respectivamente son más bajos en ambos tipos de declaraciones estratégicas, lo que según los autores del modelo de RSU utilizado en nuestra investigación es una expresión de la baja penetración de la mirada más empresarial de la responsabilidad social dentro del funcionamiento institucional.

En virtud de lo anterior, los resultados obtenidos en nuestra investigación evidencian la relevancia que puede adquirir la efectiva incorporación de los principales aspectos del modelo de RSU en los planes estratégicos institucionales, especialmente cuando las IES se adscriben a las redes interuniversitarias promotoras de la RSU en América Latina, lo que les permitirá guiar de mejor manera a sus respectivas comunidades académicas hacia una real implementación de dicho modelo, por ende, plasmarlos efectivamente en la cultura y quehacer organizacional.

Lo anterior, permitiría garantizar una mayor coherencia organizacional para mejorar la capacidad de gestionar los cambios que implica el fortalecimiento del comportamiento socialmente responsable en las IES, lo que es especialmente relevante para el caso de URSULA, que declara dentro de las consideraciones compartidas para su creación que la RSU: "es una política de gestión que permite crear coherencia entre el discurso misional institucional y la práctica cotidiana de la comunidad universitaria". Así, resulta muy recomendable que las IES que se adscriben a dicha red interuniversitaria actualicen sus planes estratégicos y evalúen efectivamente la aplicación de los aspectos centrales de la RSU en su propio quehacer institucional, para implementar políticas y estrategias institucionales más efectivas en la ejecución del modelo de la RSU.

\section{Referencias}

Arango, Olber, Moncayo, Jorge y Martí, Juan José (Eds.). (2015). Experiencias iberoamericanas en responsabilidad social universitaria. Medellín, Colombia: Funlam.

Canelón, Agrivalca (2013). Responsabilidad social universitaria 2.0. Análisis de las páginas web de universidades de AUSJAL. Revista Internacional de Relaciones Públicas, 3(5), 27-48. http://dx.doi.org/10.5783/RIRP-5-2013-03-27-48 
Escalante, Ana, Ibarra, Luz y Fonseca, César (2016). Responsabilidad social universitaria o universidad socialmente responsable: la importancia del sujeto. Revista Electrónica Diálogos Educativos, 16(31), 72-110.

Gaete, Ricardo. (2016a). Iniciativas internacionales y redes interuniversitarias de responsabilidad social universitaria. Revista Ciencia, Docencia y Tecnología, 27(54), 75-102.

Gaete, Ricardo. (2016b). La responsabilidad social universitaria en la identidad corporativa de las universidades chilenas. Un análisis de contenido. Revista Documentos y Aportes en Administración Pública y Gestión Estatal, 16(26), 43-74.

Gaete, Ricardo. (2015a). La responsabilidad social universitaria desde la perspectiva de las partes interesadas: un estudio de caso. Revista Electrónica Actualidades Investigativas en Educación, 15(1), 1-29. DOI: dx.doi.org/10.15517/aie.v15i1.17729

Gaete, Ricardo. (2015b). Responsabilidad social en el gobierno y gestión de las universidades estatales chilenas. Revista Civilizar, 15(29), 163-180.

Gaete, Ricardo. (2011). La responsabilidad social universitaria como desafío para la gestión de la educación superior: el caso de España. Revista de Educación, 355, 109-133.

Gargantini, Daniela y Zaffaroni, Cecilia. (2011). Informe final del proceso de autoevaluación de la responsabilidad social universitaria en la AUSJAL (1er Ed.). Córdoba: Alejandría Editorial.

Gargantini, Daniela y Zaffaroni, Cecilia. (2009). Políticas y sistema de autoevaluación y gestión de la responsabilidad social universitaria en AUSJAL. Córdoba: Alejandría Editorial. Recuperado de http://ausjal.org/wp-content/uploads/Pol\%C3\%ADticas-ySistemas-de-Autoevaluaci\%C3\%B3n-y-Gesti\%C3\%B3n-de-la-RSU-en-AUSJAL.pdf

Larrán, Manuel y Andrades, Francisco. (2015). Análisis de la responsabilidad social universitaria desde diferentes enfoques teóricos. Revista Iberoamericana de Educación Superior, 6(15), 91-107.

Larrán, Manuel y López, Antonio. (2010). Análisis de contenido de los planes estratégicos de las universidades públicas andaluzas bajo la perspectiva de la responsabilidad social, 175-187. En De la cuesta, M., De la Cruz, C. y Rodríguez, J.M. (Coord.), Responsabilidad Social Universitaria. La Coruña, España: Netbiblo.

Licandro, Óscar y Yepes, Sandra. (2018). La educación superior conceptualizada como bien común: El desafío propuesto por UNESCO. Revista Digital de Investigación en Docencia Universitaria, 12(1), 6-33. doi: http://dx.doi.org/10.19083/ridu.12.716

Londoño, Isabel. (2013). Responsabilidad social universitaria - Una estrategia de gestión para la educación superior. Sinapsis Revista de Investigaciones de la Escuela de Administración y Mercadotecnia del Quindío, 5(5), 135-151. 
Martí-Noguera, Juan José, Licandro, Óscar y Gaete, Ricardo. (2018). La responsabilidad social de la educación superior como bien común. Concepto y desafíos. Revista de la Educación Superior, 47(186), 1-22.

Martí, Juan José y Martí-Vilar, Manuel. (2013). Una década de responsabilidad social en Iberoamérica. Revista Española del Tercer Sector, 25, 145-162.

Muñoz, Siegfried. (2013). La responsabilidad social universitaria. Synergies, (9), 35-49.

Olarte-Mejía, Diana y Ríos-Osorio, Leonardo. (2015). Enfoques y estrategias de responsabilidad social implementadas en Instituciones de Educación Superior. Una revisión sistemática de la literatura científica de los últimos 10 años. Revista de la Educación Superior, 44(175), 19-40.

Unión de responsabilidad social universitaria Latinoamericana. (2016). Declaración oficial de creación. Recuperado de http://unionursula.org/declaracion-ursula/declaracion-ursulaespanol/

Vallaeys, François y Álvarez, Juliana. (2019). Hacia una definición latinoamericana de responsabilidad social universitaria. Aproximación a las preferencias conceptuales de los universitarios. Revista Educación XX1, 22(1), 93-116. Doi: https://doi.org/10.5944/educxx1.19442

Vallaeys, François (2018). Las diez falacias de la Responsabilidad Social Universitaria. Revista Digital de Investigación en Docencia Universitaria, 12(1), 34-58. doi: http://dx.doi.org/10.19083/ridu.12.716

Vallaeys, François, De la Cruz, Cristina y Sasia, Pedro. (2009). Responsabilidad Social Universitaria: Manual de primeros pasos. Distrito Federal, México: Mc Graw Hill. 
Revista indizada en

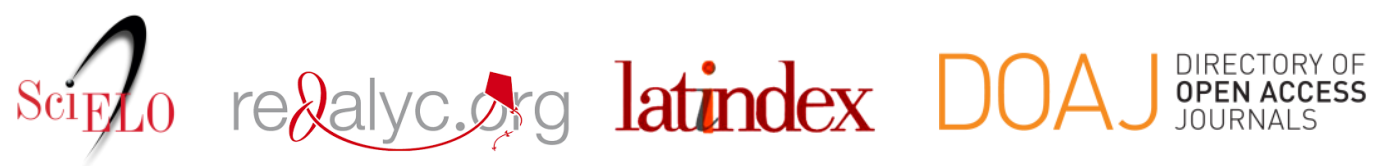

Distribuida en las bases de datos:

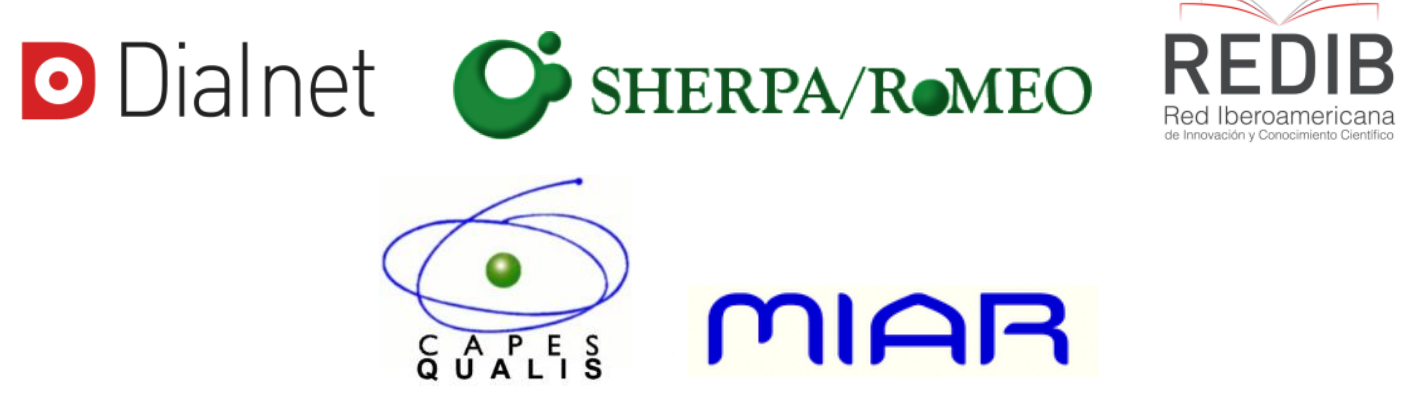

